\title{
Analisis kinerja routing OSPF dan EIGRP dengan teknik redistribution
}

\author{
Catur Budi Waluyo \\ Program Studi Teknik Elektro, Sekolah Tinggi Teknologi Adisutjipto \\ Email: catur_budiwaluyo@yahoo.co.uk
}

\begin{abstract}
As the rapid development of technology, the demand to increase the network performance becomes higher. One of the parameters of a higher network performance is the increase of data rate by determining the faster and the best way for data delivery in any network. One method was used to determine that way dynamically by using OSPF and EIGRP protocol routing. Throughput, delay, jitter, packet loss, and speed performance were counted in this research. Based on the simulation using tracer packet software, the throughput was 45.75 bps, the delay was $5.91 \mathrm{~ms}$, the jitter was $1.477 \mathrm{~ms}$, and the loss packet was 0\%. While the value of COST by data packet delivery in OSPF area was $781.25 \mathrm{kbps}$ and the metric value of data packet delivery in EIGRP area was 20 kbps. With a good QoS value, the OSPF and EIGRP routing can be implemented for this network topology.
\end{abstract}

Keywords: Routing, OSPF, EIGRP, QoS

\section{Pendahuluan}

Seiring perkembangan teknologi yang semakin pesat, tuntutan untuk meningkatkan kualitas jaringan semakin meningkat. Peningkatan ini menyebabkan para penyedia layanan jaringan berlomba untuk meningkatkan kualitas layanan dan infrastrukturnya. Salah satu mitigasi untuk meningkatkan kualitas layanan yaitu dengan meningkatkan kinerja jaringan yang ditawarkan baik dari penggunaan jaringan wireless maupun bagian router [1]. Untuk meningkatkan kualitas layanan di jaringan wireless dapat meletakkan wireless router berdasarkan pengukuran kualitas sinyal [1], [3]. Sedangkan untuk meningkatkan kinerja dari paket data dapat sampai di tujuan dan menentukan jalur tercepat dan terbaik dibutuhkan protocol routing yang tepat [5]. Pada jaringan komputer, protocol routing terdiri dari Routing dinamis dan Routing statis. Protokol OSPF dan EIGRP merupakan bagian dari protocol dinamis yang paling banyak digunakan. Protocol routing tersebut menggunakan cost dan bandwidth sebagai metric yang digunakan jaringan untuk melihat kecepatan data, throughput yang terbaik, jitter dan paket loss yang terkecil pada topologi jaringan [4],[6],[7]. Oleh karena itu, pada penelitian ini akan disimulasikan protocol routing OSPF dan EIGRP dengan menggunakan software packet tracer untuk menganalisis throughput, jitter, delay, packet loss dan kinerja kecepatannya. Kinerja kecepatan pada protocol routing OSPF dan EIGRP berdasarkan nilai COST dan Metric yang dihitung. 


\section{Metode Penelitian}

\subsection{Protocol routing}

Protocol routing merupakan suatu teknik untuk mencari jalur tercepat dan terbaik untuk mengirimkan paket data dari node pengirim ke node penerima melalui tabel routing. Protocol routing terdiri dari 2 jenis yaitu protocol routing dinamis dan protocol routing statis. Protocol routing dinamis mempunyai kelebihan antara lain tidak perlu mengetahui semua alamat jaringan yang ada, jika ada penambahan jaringan, tidak perlu konfigurasi semua router, dan hanya mengenalkan alamat jaringan yang terhubung langsung dengan routernya. Sedangkan kelebihan dari protocol routing statis antara lain beban kerja router ringan dibandingkan routing dinamis, pengiriman paket lebih cepat dan deteksi kesalahan pada topologi jaringan lebih mudah. Ada beberapa jenis protocol routing yang sering digunakan antara lain RIP (Routing Information Protocol), IGRP (Interior Gateway Routing Protocol), EIGRP (Enhanced Interior Gateway Routing Protocol), OSPF (Open Short Path First), dan BGP (Border Gateway Protocol).

\subsubsection{OSPF}

OSPF (Open Shortes Path First) merupakan protokol routing Link State (LS) yang bersifat open standar (Non Priority). OSPF dapat melakukan konvergensi secara cepat dan menentukan jalur terbaik berdasarkan nilai cost terendah. Pada OSPF, proses update dapat dilakukan secara Triggered update. Pada protocol routing ini, tidak semua informasi yang ada di router akan dikirim seluruhnya ke routerrouter lain. Hanya informasi berubah bertambah atau berkurang) saja yang akan dikirim ke semua router dalam area tersebut.

Algoritma SPF menemukan semua jalur router yang mungkin dilewati menuju tujuan. Pada jaringan ini, memungkinkan adanya pemilihan jalur/rute terpendek dan terbaik untuk pengiriman datanya sampai tujuan [9]. OSPF mendukung teknik load balancing yaitu sebuah router dapat menyeimbangkan paketnya dengan berbasis per paket yang dikirimkan. Protokol ini cocok untuk jaringan berskala besar [5].

Protocol routing OSPF dianggap sebagai protocol routing yang efisien, sehingga protokol ini umumnya diterapkan sebagai Interior Gateway Protocol (IGP) pada sistem otonom di internet. Pada OSPF dapat digunakan untuk mengamati efek serangan Denial of Service (DoS) dari pemalsuan Link State Advertisement (LSA) [8]. Untuk menghitung COST pada protocol routing OSPF dapat dilihat pada Persamaan (1) [9].

$$
\text { COST }=\frac{10^{8}}{\text { Bandwidth }}(\text { pps })
$$

\subsubsection{EIGRP}

EIGRP (Enhanced Interior Gateway Routing Protocol) merupakan sebuah protocol routing otomatis atau routing dinamis yang mampu menjaga, mengatur dan mendistribusikan informasi routing antar jaringan mengikuti setiap perubahan jaringan secara dinamis. EIGRP dibuat untuk mengatasi keterbatasan protokol IGRP. Prinsip kerja dari protocol routing EIGRP berdasarkan distance vector routing protocol, yaitu sederhana, efisien dalam pemakaian resource (memori, bandwidth,dan prosesor), dan mendukung berbagai protokol [9]. Untuk kinerja dari protocol routing EIGRP sangat bagus dengan delay dan jitter yang kecil serta bandwidth yang lebar[4],[6]. Pada protocol routing EIGRP menggunakan protokol Reliable Transport Protocol (RTP) untuk memperbarui informasi pada topologi. Untuk menghitung metric dari EIGRP terdiri dari delay dan bandwidth. EIGRP menghindari penumpukan tautan karena metric dihitung berdasarkan bandwidth terkecil pada jaringan tersebut [9]. Untuk menghitung Metric pada protocol routing EIGRP dapat dilihat pada Persamaan (2) [11]. 


$$
\begin{aligned}
& \text { Metric }=\text { Bandwidth }+ \text { delay } \\
& \text { Metric }=256 * \frac{10^{7}}{\min (\text { bandwidth })}+\sum \frac{\text { delay }}{10}
\end{aligned}
$$

\subsubsection{Quality of Service ( $Q o S$ )}

Parameter QoS terdiri dari throughput, delay, jitter, dan packet loss. Parameter throughput didefinisikan sebagai kecepatan rata-rata data efektif yang diterima oleh node penerima pada suatu selang waktu pengamatan tertentu [2],[3]. Untuk melihat kemampuan suatu jaringan dalam melakukan pengiriman data dapat berdasarkan nilai Throughput yang didapatkan yang dapat dihitung dengan Persamaan (3). Sedangkan parameter untuk kategori throughput dapat dilihat pada Tabel 1.

$$
\text { Throughput }=\frac{\text { Packet_data_diterima }}{\text { Total_waktu_pengiriman }}(\text { bps })
$$

Tabel 1. Parameter kategori throughput

\begin{tabular}{ccc}
\hline Kategori Throughput & Throughput (bps) & Indeks \\
\hline Sangat Bagus & $100 \mathrm{bps}$ & 4 \\
Bagus & $75 \mathrm{bps}$ & 3 \\
Sedang & $50 \mathrm{bps}$ & 2 \\
Jelek & $<25 \mathrm{bps}$ & 1 \\
\hline
\end{tabular}

Delay didefinisikan sebagai waktu tunda yang dibutuhkan oleh paket data oleh dari pengirim ke penerima. Delay dipengaruhi oleh perbedaan jarak. Untuk mengetahui delay yang diakibatkan oleh proses transmisi dari satu titik ke titik tujuan maka dapat dilihat pada Persamaan (4). Sedangkan parameter untuk kategori delay dapat dilihat pada Tabel 2.

$$
\text { Delay }=\frac{\text { Total_delay }}{\text { Total_paket_diterima }}
$$

Tabel 2. Parameter kategori Delay

\begin{tabular}{ccc}
\hline Kategori Delay & Delay $(\mathrm{ms})$ & Indeks \\
\hline Sangat Bagus & $<150 \mathrm{~ms}$ & 4 \\
Bagus & $150 \mathrm{~ms} \mathrm{~s} / \mathrm{d} 300 \mathrm{~ms}$ & 3 \\
Sedang & $300 \mathrm{~ms} \mathrm{~s} / \mathrm{d} 450 \mathrm{~ms}$ & 2 \\
Jelek & $>450 \mathrm{~ms}$ & 1 \\
\hline
\end{tabular}

Jitter didefinisikan sebagai variasi delay yang diakibatkan oleh panjang antrian dalam suatu pengolahan data dan penghimpunan ulang paket data di akhir pengiriman akibat kegagalan sebelumnya. Jitter sering disebut latency yang menunjukan banyaknya variasi delay. Untuk menghitung jitter digunakan Persamaan (5). Sedangkan parameter untuk kategori jitter dapat dilihat pada Tabel 3.

$$
\text { Jitter }=\frac{\text { Total_variasi_delay }}{\text { Total_paket_diterima }}
$$


Tabel 3. Parameter kategori jitter

\begin{tabular}{ccc}
\hline Kategori Jitter & Jitter $(\mathrm{ms})$ & Indeks \\
\hline Sangat Bagus & $0 \mathrm{~ms}$ & 4 \\
Bagus & $0 \mathrm{~ms} \mathrm{~s} / \mathrm{d} 75 \mathrm{~ms}$ & 3 \\
Sedang & $75 \mathrm{~ms} \mathrm{~s} / \mathrm{d} 125 \mathrm{~ms}$ & 2 \\
Jelek & $125 \mathrm{~ms} \mathrm{~s} / \mathrm{d} 225 \mathrm{~ms}$ & 1 \\
\hline
\end{tabular}

Packet loss yaitu jumlah prosentase paket yang hilang dalam proses pengiriman data dari sumber trafik ke node tujuan. Packet loss dapat terjadi karea tabrakan antar paket dalam jaringan. Untuk menghitung packet loss pada sistem ini dengan menggunakan Persamaan (6). Sedangkan parameter untuk packet loss dapat dilihat pada Tabel 4.

$$
\text { Packet_Loss }=\frac{\text { Paket_data_dikirim }- \text { Paket_data_diterima }}{\text { Paket_data_dikirim }} \times 100 \%
$$

Tabel 4. Parameter kategori packet loss

\begin{tabular}{ccc}
\hline Kategori Packet loss & Packet loss $(\%)$ & Indeks \\
\hline Sangat Bagus & 0 & 4 \\
Bagus & 3 & 3 \\
Sedang & 15 & 2 \\
Jelek & 25 & 1 \\
\hline
\end{tabular}

\subsubsection{Desain simulasi dan implementasi}

Perancangan topologi yang dilakukan dibagi menjadi 2 area protocol routing yaitu protocol routing OSPF dan EIGRP. Perangkat lunak yang digunakan pada simulasi ini yaitu software packet tracer. Sedangkan komponen yang digunakan dalam simulasi ini terdiri dari 2 buah server, 7 buah router, 4 buah komputer dan 4 buah switch dan dapat dilihat pada Gambar 1. Sedangkan parameter alamat Internet Protocol (IP) yang digunakan pada masing-masing interface router dapat dilihat pada Tabel 5 dan Tabel 6.

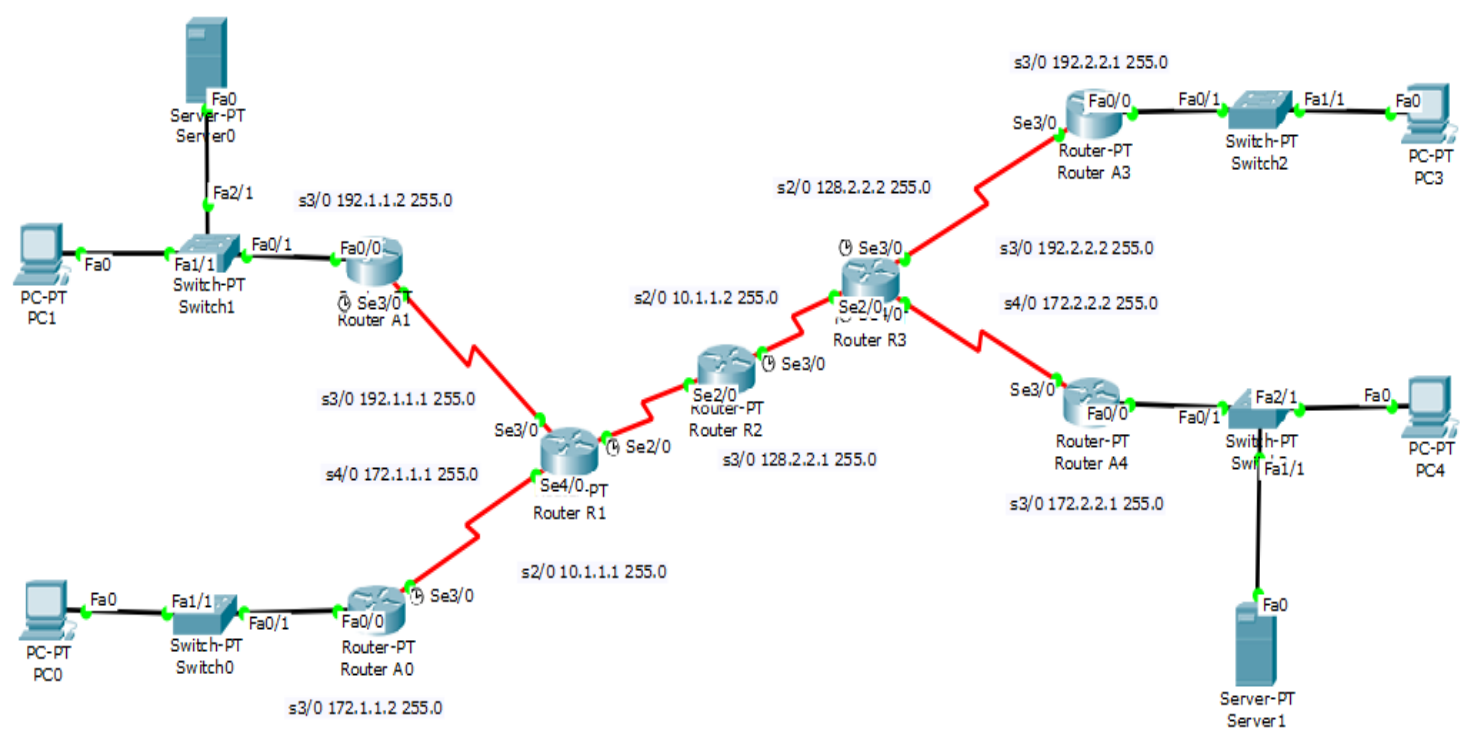

Gambar 1. Topologi simulasi menggunakan software Packet Tracer. 
Tabel 5. Pengaturan konfigurasi Router R1, R2, dan R3

\begin{tabular}{llll}
\hline Interface & Router $\mathrm{R} 1$ & Router $\mathrm{R} 2$ & Router $\mathrm{R} 3$ \\
\hline Interface S2/0 & $10.1 .1 .1 / 24$ & $10.1 .1 .2 / 24$ & $128.2 .2 .2 / 24$ \\
Interface S3/O & $192.1 .1 .1 / 24$ & $128.2 .2 .1 / 24$ & $192.2 .2 .2 / 24$ \\
Interface S4/0 & $172.1 .1 .1 / 24$ & & $172.2 .2 .2 / 24$ \\
Interface loO & $1.1 .1 .1 / 32$ & $2.2 .2 .2 / 32$ & $3.3 .3 .3 / 32$ \\
\hline
\end{tabular}

Tabel 6. Pengaturan konfigurasi Router A1, A2, A3 dan A4

\begin{tabular}{lllll}
\hline Interface & Router A1 & Router A2 & Router A3 & Router A4 \\
\hline Interface S3/0 & $192.1 .1 .2 / 24$ & $172.1 .1 .2 / 24$ & $192.2 .2 .1 / 24$ & $172.2 .2 .1 / 24$ \\
Interface FO/O & $192.168 .1 .1 / 24$ & $192.168 .2 .1 / 24$ & $192.168 .3 .1 / 24$ & $192.168 .4 .1 / 24$ \\
\hline
\end{tabular}

\section{Hasil dan Pembahasan}

\subsection{Pengujian Quality of Service (QoS)}

\subsubsection{Throughput}

Pada pengujian throughput digunakan untuk mengetahui kecepatan rata-rata data efektif yang diterima oleh node penerima pada suatu selang waktu pengamatan tertentu. Jumlah trafik yang dikirim menunjukkan banyaknya data yang dikirim pada masing-masing protocol routing dengan satuan bit per second (bps) [6]. Throughput dapat dihitung dengan Persamaan (3). Untuk hasil pengujian throughput dapat dilihat pada Tabel 7. Rerata nilai throughput dari 12 kali pengujian sebesar 45.75bps. Berdasarkan parameter kategori throughput pada Tabel 1 termasuk sedang.

Tabel 7. Hasil pengujian throughput.

\begin{tabular}{lrrrc}
\hline & \multicolumn{3}{c}{ Throughput } & \multirow{2}{*}{ Keterangan } \\
\cline { 2 - 3 } & \multicolumn{1}{c}{ Min(kbps) } & Max(kbps) & Average $(\mathrm{kbps})$ & \\
\hline PC0-PC1 & 256 & 32 & 60,95238 & OSPF \\
PC0-PC2 & 45,71429 & 24,38095 & 35,06849 & OSPF-EIGRP \\
PC0-PC3 & 44,91228 & 21,51261 & 31,60494 & OSPF-EIGRP \\
PC1-PC0 & 213,3333 & 40 & 62,43902 & OSPF \\
PC1-PC2 & 35,55556 & 26,94737 & 34,59459 & OSPF-EIGRP \\
PC1-PC3 & 47,40741 & 30,84337 & 40,63492 & OSPF-EIGRP \\
PC2-PC3 & 88,27586 & 32,82051 & 59,53488 & EIGRP \\
PC2-PC0 & 51,2 & 36,05634 & 42,66667 & EIGRP-OSPF \\
PC2-PC1 & 46,54545 & 37,10145 & 41,96721 & EIGRP-OSPF \\
PC3-PC2 & 134,7368 & 33,24675 & 59,53488 & EIGRP \\
PC3-PC0 & 45,71429 & 29,76744 & 41,96721 & EIGRP-OSPF \\
PC3-PC1 & 46,54545 & 29,42529 & 38,20896 & EIGRP-OSPF \\
\hline
\end{tabular}




\subsubsection{Delay}

Pengujian delay digunakan untuk mengetahui waktu yang dibutuhkan untuk mengirimkan paket data dari pengirim ke penerima. Besarnya delay menunjukkan waktu tunda paket yang disebabkan oleh proses transmisi dari satu titik ke titik lainnya [6]. Penundaan diperoleh dari perbedaan antara waktu pengiriman antara satu paket dengan paket yang lain. Untuk mengetahui rerata delay dapat dihitung dengan Persamaan (4). Untuk hasil perhitungan delay dapat disajikan pada Tabel 8. Berdasarkan Tabel 8 dapat dilihat bahwa rata-rata delay dari 12 pengujian sebesar $5.91 \mathrm{~ms}$. Berdasarkan parameter kategori delay pada Tabel 2 termasuk sangat bagus.

\subsubsection{Jitter}

Pada pengukuran jitter digunakan untuk mengetahui variasi delay yang diakibatkan oleh panjang antrian dalam suatu pengolahan data dan penghimpunan ulang paket data di akhir pengiriman akibat kegagalan sebelumnya atau tabrakan data dari sumber ke tujuan [6]. Untuk mengetahui nilai jitter maka dapat dihitung dengan Persamaan (5). Untuk hasil perhitungan jitter dapat disajikan pada Tabel 9. Berdasarkan Tabel 9 dapat dilihat bahwa rata-rata nilai jitter dari 12 pengujian sebesar 1.477 ms. Berdasarkan Tabel 3 , nilai rerata jitter sebesar $1.477 \mathrm{~ms}$ dalam kategori bagus dengan nilai indeks 3 .

Tabel 8. Hasil pengujian paket Delay

\begin{tabular}{crrrl}
\hline \multirow{2}{*}{ HOST } & \multicolumn{3}{c}{ Delay } & \multirow{2}{*}{ Keterangan } \\
\cline { 2 - 4 } PC0-PC1 & 1 & 8 & 4,2 & OSPF \\
PC0-PC2 & 5,6 & 10,5 & 7,3 & OSPF-EIGRP \\
PC0-PC3 & 5,7 & 11,9 & 8,1 & OSPF-EIGRP \\
PC1-PC0 & 1,2 & 6,4 & 4,1 & OSPF \\
PC1-PC2 & 7,2 & 9,5 & 7,4 & OSPF-EIGRP \\
PC1-PC3 & 5,4 & 8,3 & 6,3 & OSPF-EIGRP \\
PC2-PC3 & 2,9 & 7,8 & 4,3 & EIGRP \\
PC2-PC0 & 5 & 7,1 & 6 & EIGRP-OSPF \\
PC2-PC1 & 5,5 & 6,9 & 6,1 & EIGRP-OSPF \\
PC3-PC2 & 1,9 & 7,7 & 4,3 & EIGRP \\
PC3-PC0 & 5,6 & 8,6 & 6,1 & EIGRP-OSPF \\
PC3-PC1 & 5,5 & 8,7 & 6,7 & EIGRP-OSPF \\
\hline
\end{tabular}

Tabel 9. Hasil pengujian Jitter

\begin{tabular}{ccccc}
\hline \multirow{2}{*}{ HOST } & \multicolumn{3}{c}{ Jitter } & \multirow{2}{*}{ Keterangan } \\
\cline { 2 - 4 } & Min(ms) & $\max (\mathrm{ms})$ & average $(\mathrm{ms})$ & OSPF \\
\hline PC0-PC1 & 0,25 & 2 & 1,05 & OSPF-EIGRP \\
PC0-PC2 & 1,4 & 2,625 & 1,825 & OSPF-EIGRP \\
PC0-PC3 & 1,425 & 2,975 & 2,025 & OSPF \\
PC1-PC0 & 0,3 & 1,6 & 1,025 & OSPF-EIGRP \\
PC1-PC2 & 1,8 & 2,375 & 1,85 & OSPF-EIGRP \\
PC1-PC3 & 1,35 & 2,075 & 1,575 & EIGRP \\
PC2-PC3 & 0,725 & 1,95 & 1,075 & EIGRP-OSPF \\
PC2-PC0 & 1,25 & 1,775 & 1,5 & \\
\hline
\end{tabular}




\begin{tabular}{ccccc}
\hline PC2-PC1 & 1,375 & 1,725 & 1,525 & EIGRP-OSPF \\
PC3-PC2 & 0,475 & 1,925 & 1,075 & EIGRP \\
PC3-PC0 & 1,4 & 2,15 & 1,525 & EIGRP-OSPF \\
PC3-PC1 & 1,375 & 2,175 & 1,675 & EIGRP-OSPF \\
\hline
\end{tabular}

\subsubsection{Packet Loss}

Pada pengujian packet loss digunakan untuk mengetahui jumlah prosentase paket yang hilang dalam proses pengiriman data dari sumber ke tujuan. Packet loss dapat terjadi karena tabrakan dalam proses pengiriman, interferensi, tabrakan data, kesalahan dan lainnya [6]. Untuk mengetahui nilai packet loss maka dapat dihitung dengan persamaan (3). Untuk hasil perhitungan dapat disajikan pada Tabel 10. Pengukuran packet loss dilakukan dengan 12 pengujian dengan masing-masing pengujian dilakukan sebanyak 5 kali. Rerata nilai packet loss dari 12 pengujian dengan masing-masing 5 kali pengujian sebesar 0\%. Berdasarkan parameter kategori packet loss pada Tabel 4, maka dapat dikategorikan sangat bagus dengan nilai indeks 4 .

Tabel 10. Hasil pengujian Packet Loss

\begin{tabular}{|c|c|c|c|c|c|}
\hline \multirow{2}{*}{ HOST } & \multicolumn{5}{|c|}{ Packets Loss } \\
\hline & 1 & 2 & 3 & 4 & 5 \\
\hline PC0-PC1 & $0 \%$ & $0 \%$ & $0 \%$ & $0 \%$ & $0 \%$ \\
\hline PC0-PC2 & $0 \%$ & $0 \%$ & $0 \%$ & $0 \%$ & $0 \%$ \\
\hline PC0-PC3 & $0 \%$ & $0 \%$ & $0 \%$ & $0 \%$ & $0 \%$ \\
\hline PC1-PC0 & $0 \%$ & $0 \%$ & $0 \%$ & $0 \%$ & $0 \%$ \\
\hline PC1-PC2 & $0 \%$ & $0 \%$ & $0 \%$ & $0 \%$ & $0 \%$ \\
\hline PC1-PC3 & $0 \%$ & $0 \%$ & $0 \%$ & $0 \%$ & $0 \%$ \\
\hline PC2-PC3 & $0 \%$ & $0 \%$ & $0 \%$ & $0 \%$ & $0 \%$ \\
\hline PC2-PC0 & $0 \%$ & $0 \%$ & $0 \%$ & $0 \%$ & $0 \%$ \\
\hline PC2-PC1 & $0 \%$ & $0 \%$ & $0 \%$ & $0 \%$ & $0 \%$ \\
\hline PC3-PC2 & $0 \%$ & $0 \%$ & $0 \%$ & $0 \%$ & $0 \%$ \\
\hline PC3-PC0 & $0 \%$ & $0 \%$ & $0 \%$ & $0 \%$ & $0 \%$ \\
\hline PC3-PC1 & $0 \%$ & $0 \%$ & $0 \%$ & $0 \%$ & $0 \%$ \\
\hline
\end{tabular}

\subsection{Pengujian Redistribute OSPF dan EIGRP}

Perhitungan topologi jaringan redistribute pada routing OSPF ke OSPF dan EIGRP ke EIGRP dengan parameter perhitungan antara cost di area OSPF dan metric di area EIGRP. Routing redistribute ini sangat penting dalam proses pengabungan antara dua jaringan yang berbeda, untuk menentukan parameter hitungan cost pada OSPF dan metric pada EIGRP dengan cara show interface s3/0.

\subsubsection{Area OSPF}

Jalur pengiriman paket data dari area OSPF ditandai dengan tanda anak panah pada Router A0 ke R2 yang melewati R1 dan pada Router A1 ke R2 yang melewati R1 seperti yang disajikan pada Gambar 2. Untuk kecepatan bandwidth pada router pada area OSPF dapat dilihat pada Gambar 3. Berdasarkan Gambar 2. Dapat dilihat bahwa arah pengiriman paket data dari Router A0 menuju ke Router R1 dan 
Paket data dari Router A1 menuju ke Router R1. Kemudian dari Router R1 menuju Router R2 dengan kecepatan bandwidth yang sama yaitu 128kbs. Untuk nilai COST dapat dihitung dengan Persamaaan (1) di dapat nilai sebesar 781.25Kbps.

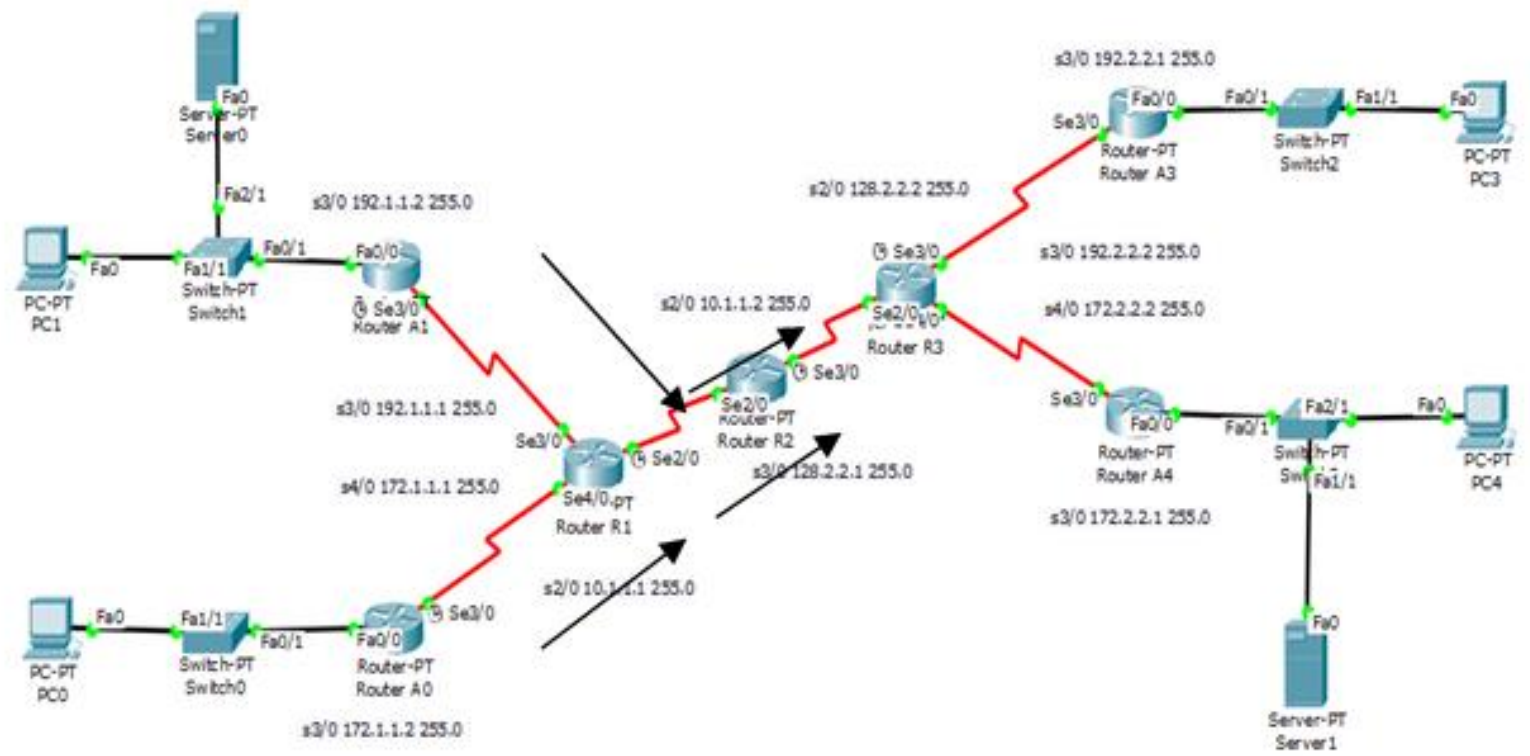

Gambar 2. Jalur pengiriman paket data dari area OSPF

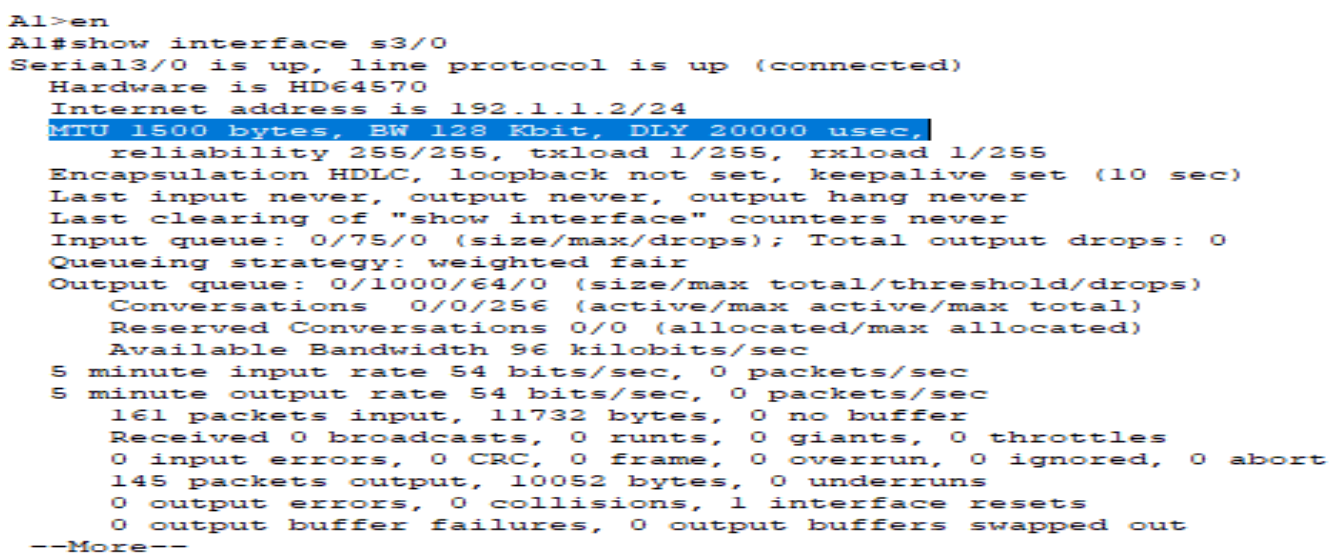

Gambar 3. Tampilan tes ping pada Router R1.

\subsubsection{EIGRP}

Jalur pengiriman paket data dari area EIGRP ditandai dengan tanda anak panah pada Router A3 ke R2 yang melewati R3 dan pada Router A4 ke R2 yang melewati R3 seperti yang disajikan pada Gambar 4. Untuk nilai Metric dapat dihitung dengan Persamaaan (2) dengan nilai delay yang sangat kecil maka pada perhitungan disini nilai delay diabaikan dan didapatkan nilai metric sebesar 20kbps.

$$
\begin{aligned}
& \text { Metric }=256 *\left[\frac{10^{7}}{128000}+0\right] \\
& \text { Metric }=256 *(78.16) \\
& \text { Metric }=20000
\end{aligned}
$$




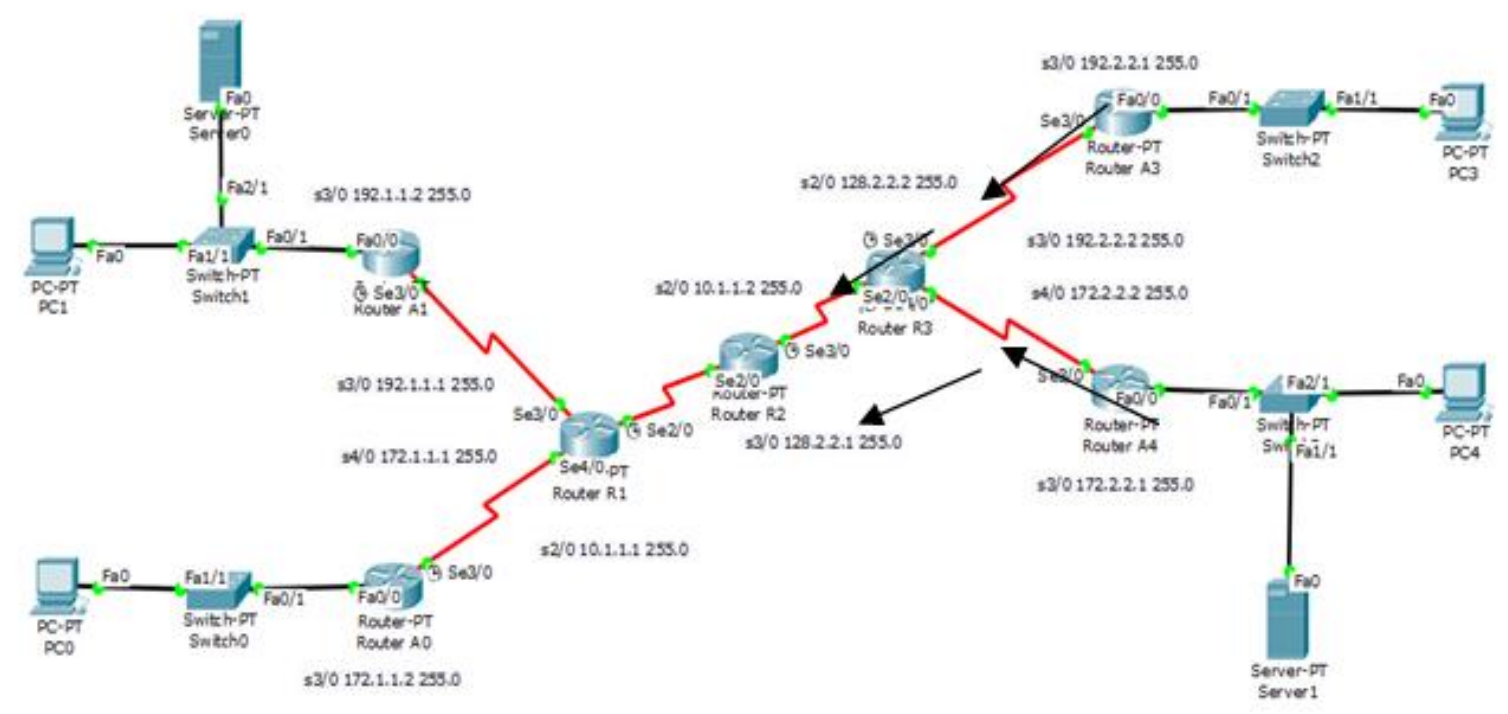

Gambar 4. Jalur pengiriman paket data dari area EIGRP

\section{Kesimpulan}

Berdasarkan hasil pengujian dari simulasi topologi jaringan dengan teknik redistribution untuk routing OSPF dan EIGRP didapatkan Quality of Service yang menunjukkan nilai rerata throughput sebesar 45.75bps, nilai rerata delay sebesar $5.91 \mathrm{~ms}$, nilai rerata jitter sebesar $1.477 \mathrm{~ms}$ dan nilai packet loss sebesar 0\%. Sedangkan nilai COST yang didapat pada pengiriman paket data di area OSPF sebesar $781.25 \mathrm{kbps}$ dan nilai metric pengiriman paket data di area EIGRP sebesar 20kbps. Dengan nilai QoS yang bagus, sehingga routing OSPF dan EIGRP dapat digunakan pada topologi jaringan ini.

\section{Daftar Pustaka}

[1] Waluyo, C. B., Erik, A., \& Astuti, Y. (2019). Performance Analysis of Wireless Local Area Network Using Router Tenda N-300. Compiler, 8(1), 1-10.

[2] Rizal M , Purwanto Y, Sholekan. 2012. Perancangan Aplikasi Synchronous Elearning dengan fasilitas video conference, chatting,dan presentasi online berbasis web. Jurnal Proyek Akhir IT Telkom. Bandung.

[3] Waluyo, C. B. (2014). Analisa Performansi Dan Coverage Wireless Local Area Network 802.11 B/G/N Pada Pemodelan Sistem E-Learning. Pros. Semin. Nas. Apl. Sains Teknol., no. November, 69-74.

[4] Nur Fatin Nadhirah Norazlan, Ruhani Ab. Rahman, Murizah Kassim, Abd Razak Mahmud, "Virtual Private Network Load Balancing Using OSPF Routing", 978-1-7281-5033-8/20/,pp 164-169, IEEE, 2020

[5] Dindin Mahpudin, S. Indriani L., Analisis Kinerja Routing EIGRP dan OSPF Menggunakan cisco packet tracer, Jurnal Sistem Komputer unikom - komputika, Volume 7 No. 1- 2018, 2018

[6] Andrew Fiade, Muhammad Aldi Agustian, Siti Ummi Masruroh, Analysis of Failover Link System Performance in OSPF, EIGRP, RIPV2 Routing Protocol with BGP, The 7th International Conference on Cyber and IT Service Management (CITSM 2019), IEEE, 2019

[7] Asad Ali Khan, Majid Hussain, Muhammad Zafrullah, Ali Ahmad, Performance Analysis of OSPF and Hybrid Networks, 978-1-5386-1556-0/17, IEEE, 2017

[8] Daniel S. Robbins, Using Protocol Redundancy to Enhance OSPF Network System Survivability, 78-1-5386-6133-8/18, IEEE, 2018 
[9] Athira M, Lekha Abraham,Sangeetha R.G, Study on Network Performance of Interior Gateway Protocols - RIP, EIGRP and OSPF, 978-1-5090-5913-3/17, pp 344-348, 2017 International Conference on Nextgen Electronic Technologies, IEEE, 2017.

[10] Siti Ummi Masruroh, Khairul Hamdi Putra Widya, Andrew Fiade, Imelda Ristanti Julia, Performance Evaluation DMVPN Using Routing Protocol RIP, OSPF, And EIGRP, The 6th International Conference on Cyber and IT Service Management (CITSM 2018), IEEE, 2018

[11] Cisco.com. (2020, 9 September). Enhanced Interior Gateway Routing Protocol. Diakses pada 4 November 2020 dari https://www.cisco.com/c/en/us/support/docs/ip/enhanced-interior-gatewayrouting-protocol-eigrp/16406-eigrp-toc.html 